\title{
Sol-Gel Deposition and Characterization of Lead Zirconate Titanate Thin Film Using Different Commercial Sols
}

\author{
Masaaki Moriyama, ${ }^{1 *}$ Kentaro Totsu, ${ }^{1}$ and Shuji Tanaka ${ }^{1,2}$ \\ ${ }^{1}$ Micro System Integration Center, Tohoku University, \\ 519-1176, Aza-Aoba, Aramaki, Aoba-ku, Sendai, Miyagi 980-0845, Japan \\ ${ }^{2}$ Department of Robotics, Division of Mechanical Engineering, Tohoku University, \\ 6-6-01 Aza-Aoba, Aramaki, Aoba-ku, Sendai, Miyagi 980-8579, Japan
}

(Received May 2, 2019; accepted July 23, 2019)

Keywords: lead zirconate titanate (PZT), sol-gel method, rapid thermal annealing (RTA), X-ray diffraction (XRD), ferroelectric property, piezoelectric constant

The sol-gel technique is a major deposition method of lead zirconate titanate (PZT), because of its good uniformity and simplicity. At present, different PZT sols are commercially available, and users are interested in which sol best fits their application and deposition tool. In this study, PZT thin films were deposited using different commercial sols, and their characteristics were evaluated and compared in terms of film thickness, crystal orientation, and ferroelectric property. We found that a rapid thermal annealing (RTA) temperature of $650{ }^{\circ} \mathrm{C}$ and a drying temperature of $180{ }^{\circ} \mathrm{C}$ were suitable as starting conditions regardless of the PZT sol. Under these conditions, the piezoelectric constant $d_{31}$ is more than $75 \mathrm{pm} / \mathrm{V}$. Optimization can be carried out efficiently by each user under these conditions.

\section{Introduction}

Lead zirconate titanate (PZT) thin films are widely used in MEMS transducers. ${ }^{(1-6)}$ PZT film forming methods include metal organic chemical vapor deposition (MO-CVD), ${ }^{(7)}$ sputter deposition, ${ }^{(8)}$ and the sol-gel method. ${ }^{(9)}$ The last is widely used because of its good uniformity and simplicity. At present, a number of PZT sols are commercially available, but from a user's standpoint, a major concern is whether the sol is suitable for their specific application and deposition apparatus. However, no report has been found on the comparison of multiple commercial PZT sols under the same conditions. In addition, it is also important to determine the deposition conditions optimal for a new sol.

In this study, PZT films were deposited using three types of commercially available sol, and their characteristics were evaluated. The film deposition conditions were systematically changed using an automatic sol-gel deposition machine in the Micro System Integration Center ( $\mu$ SIC) of Tohoku University.

*Corresponding author: e-mail: mmoriyama@mems.mech.tohoku.ac.jp https://doi.org/10.18494/SAM.2019.2420 


\section{Experimental Methods}

\subsection{Automatic sol-gel deposition machine}

The sol-gel method is a technique for obtaining a ceramic thin film from a sol in which the alkoxides of metals are dissolved in a solvent. The sol is spread typically by spin coating, gelled by heating, and pyrolyzed several $(M)$ times. Then, the pyrolyzed thin film is crystallized by rapid thermal annealing (RTA). This unit process is repeated several $(N)$ times. Figure 1 shows the process of PZT film deposition by the sol-gel method. ${ }^{(10)}$

The automatic PZT film deposition tool (Techno Fine Co., Ltd., Japan) used in this study is shown in Fig. 2. It comprises a robot arm for transferring the wafer, a wafer stage, a wafer centering mechanism, a spin coater, dispensers, low- and high-temperature drying ovens, an RTA furnace, and a touch panel screen controller. Sol-gel film is automatically formed on wafers of 4- or 2-inch diameter following a registered recipe.

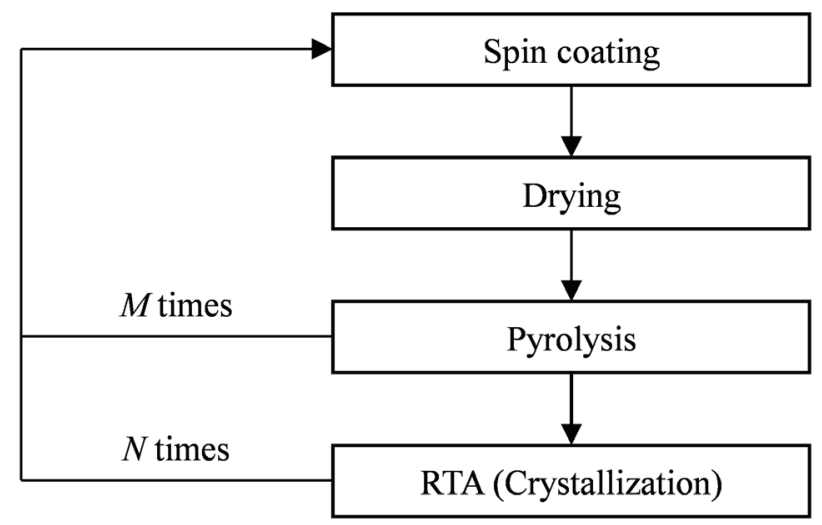

Fig. 1. Deposition by sol-gel method.

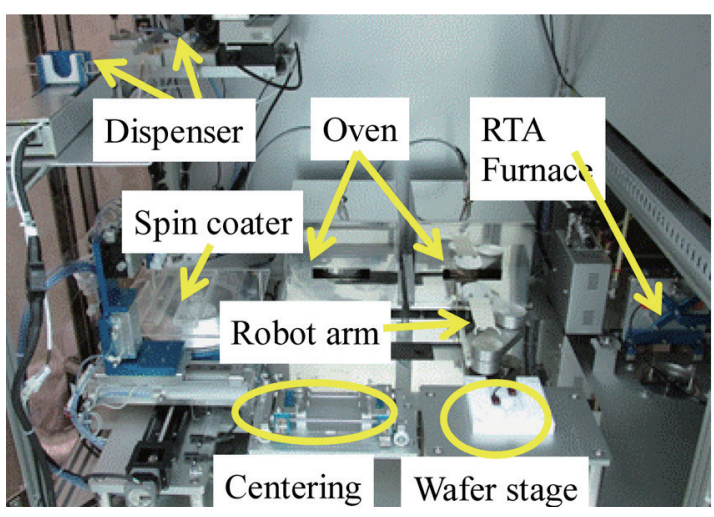

(a)

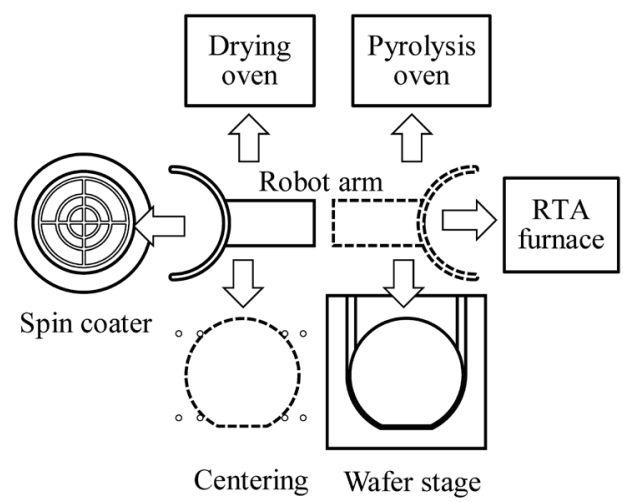

(b)

Fig. 2. (Color online) (a) Photograph and (b) diagram of automatic sol-gel deposition apparatus. 


\subsection{Deposition of Pt electrode film}

A PZT film is deposited on a Pt thin film, which is used as a bottom electrode. The crystal orientation of PZT film is strongly affected by the quality of the Pt thin film. In this study, the Pt film of the bottom electrode is prepared as follows. A 4-inch-diameter n-type Si wafer of $300 \mu \mathrm{m}$ thickness is thermally oxidized at $1100{ }^{\circ} \mathrm{C}$. The Pt film of $100 \mathrm{~nm}$ thickness is deposited at $600{ }^{\circ} \mathrm{C}$ using a DC sputtering machine (Youtec Co., Ltd., Japan). Then, in order to improve the adhesion and crystal orientation of the Pt film, it is annealed for $10 \mathrm{~min}$ at $800{ }^{\circ} \mathrm{C}$ in a pressurized oxygen atmosphere of $0.9 \mathrm{MPa}$. The Pt film sputtering conditions are shown in Table 1. The orientation of the Pt film is (111) as shown in Fig. 3, and the full width at half maximum (FWMH) is $1.8^{\circ}$.

\subsection{Deposition of PZT film}

In this study, we prepared three PZT sols from domestic manufacturers: Sol-A (Mitsubishi Materials, E1 series), Sol-B (Youtec, Coating Solution PZT), and Sol-C (Kojundo Chemical Laboratory, PZT-20). The PZT concentrations are 10, 10, and $20 \mathrm{wt} \%$, respectively. Sol-A and Sol-B are solutions obtained by hydrolyzing and polymerizing metal organic compounds such as alkoxides and dispersing them in a colloidal solution. Sol-C is a solution of a metal organic compound, mainly an organic acid salt, in an organic solvent. Each sol has a morphotropic phase boundary (MPB) composition ( $\mathrm{Pb}: \mathrm{Zr}: \mathrm{Ti}=110-120: 52: 48)$. Note that Sol-B is easily hydrolyzed and rapidly precipitates.

Table 1

Sputtering conditions for Pt bottom electrode film.

\begin{tabular}{ccccc}
\hline Ar flow rate & $\begin{array}{c}\text { DC power } \\
\text { (4-inch target) }\end{array}$ & $\begin{array}{c}\text { Target-sample } \\
\text { distance }\end{array}$ & Pressure & Sputtering time \\
\hline $25 \mathrm{sccm}$ & $125 \mathrm{~W}$ & $80 \mathrm{~mm}$ & $0.80 \mathrm{~Pa}$ & $5 \mathrm{~min}$ \\
\hline
\end{tabular}

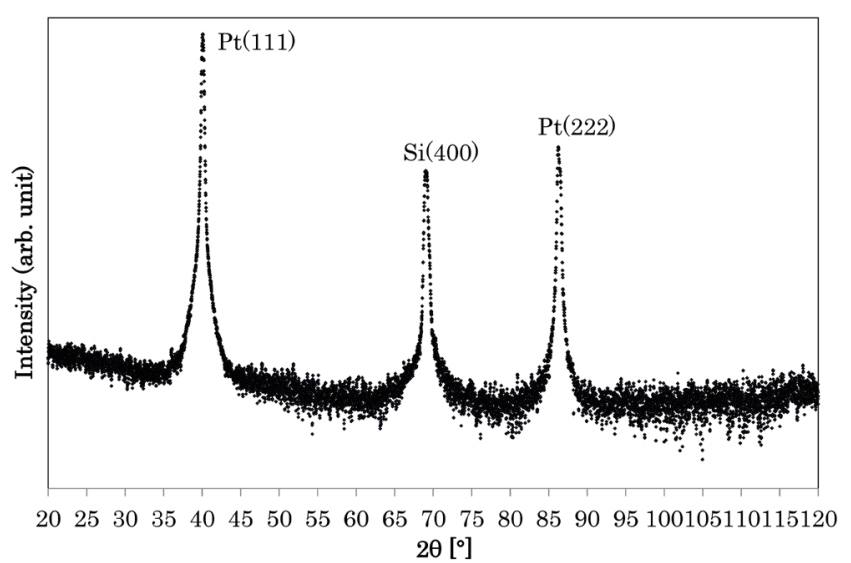

Fig. 3. XRD spectrum for Pt bottom electrode film. 
The rotational speed of spin coating is $3000 \mathrm{rpm}$ for all sols. $1.2 \mathrm{~mL}$ of sol is dispensed each time after a dummy dosage of $0.3 \mathrm{~mL}$. In a preliminary experiment, Sol-C spun at 2000 $\mathrm{rpm}$, which is recommended by the manufacturer, cracked in our deposition tool, and a higher rotational speed was selected. The drying temperature after spin coating is changed from 120 to $210{ }^{\circ} \mathrm{C}$ in steps of $30{ }^{\circ} \mathrm{C}$. After drying for $2 \mathrm{~min}$, pyrolysis is performed at $350{ }^{\circ} \mathrm{C}$ for 5 min. The process from spin coating to pyrolysis is repeated 3 times $(M=3$ in Fig. 1) for Sol-A and Sol-C and 5 times ( $M=5$ in Fig. 1) for Sol-B. Considering the concentration of sols, the repetition numbers $(M)$ from spin coating to pyrolysis were initially 5 for Sol-A (10 wt\%) and Sol-B (10 wt \%) and 3 for Sol-C (20 wt \%). However, Sol-A showed cracks after the following RTA, which is why the above condition was adopted.

The PZT film is crystallized by RTA for $10 \mathrm{~min}$ after pyrolysis. The RTA temperature is changed from 550 to $750{ }^{\circ} \mathrm{C}$ in steps of $50{ }^{\circ} \mathrm{C}$. It is known that the pyrochlore phase appears in a temperature zone of $400-500{ }^{\circ} \mathrm{C}$, which should be quickly surpassed. The temperature increase rate is $30{ }^{\circ} \mathrm{C} / \mathrm{s}$ after $100{ }^{\circ} \mathrm{C}$. The temperature is held once at $100{ }^{\circ} \mathrm{C}$ for $10 \mathrm{~s}$ to protect the infrared lamp of the gold image furnace. The appropriate drying and RTA temperatures were experimentally determined. The target thickness of the PZT film is $1 \mu \mathrm{m}$.

\subsection{Evaluation method of PZT thin film}

X-ray diffraction (XRD) (D8 DISCOVER, Bruker AXS GmbH, Germany) is used to evaluate PZT films prepared at different drying and RTA temperatures. Then, further evaluation is carried out for a $1-\mu \mathrm{m}$-thick PZT film made of each sol under the optimal conditions. Hereinafter, the PZT films made of Sol-A, Sol-B, and Sol-C are referred to as Samples A, B, and C, respectively.

Samples A, B, and C are again evaluated by XRD at radial positions ( $r$ ) 0 (center), 20, and 40 $\mathrm{mm}$. Then, the ferroelectric characteristics of each sample are measured using a Sawyer tower circuit with a reference capacitor of $200 \mathrm{nF}$. A $50 \mathrm{~Hz}$ triangular wave of $\pm 30 \mathrm{~V}$ amplitude is applied to each sample.

The piezoelectric constant $d_{33, f}$ is measured using a double-laser-beam piezoelectric measurement system (TF Analyzer 2000E, aixACT Systems GmbH, Germany). ${ }^{(11)}$ The system irradiates laser light from both sides onto the sample and measures the change in thickness owing to the piezoelectric response to an AC pulse electric field. The frequency and amplitude of the AC pulse are $1 \mathrm{kHz}$ and $\pm 20 \mathrm{~V}$, respectively. $d_{33, f}$ is obtained from the applied voltage, the film thickness of PZT, and the measured displacement. Also, the piezoelectric constant $d_{31}$ is estimated from the piezoelectric constant $d_{33, f}$.

To measure the ferroelectric characteristic and piezoelectric constant, the bottom $\mathrm{Pt}$ electrode film is exposed and an upper Pt electrode film is formed on the sample surface. The Pt film is deposited using a sputter tool, and the top Pt film is etched by Ar ion milling (NS/20IBE, Hakuto Co., Ltd., Japan) using a photoresist mask. Then, the PZT film is etched by a wet etching solution $\left(2 \% \mathrm{HF}: 37 \% \mathrm{HCl}: \mathrm{H}_{2} \mathrm{O}=10: 30: 60\right)$ to expose the bottom Pt electrode film. 


\section{Experimental Results}

\subsection{PZT film thickness per spin coating}

The PZT film thickness was measured at radii of $0,10,20,30$, and $40 \mathrm{~mm}$ using the etched openings to access the Pt bottom electrode film. Figure 4 shows the film thickness per spin coating for each sol. The concentrations of Sol-A and Sol-B are both $10 \mathrm{wt} \%$ and that of Sol-C is $20 \mathrm{wt} \%$, which are well reflected in Fig. 4. Sol-C is the most efficient in terms of deposition time, and a $300 \mathrm{~nm}$ thickness of the film is obtained by a single cycle (Fig. 1), comprising 3 repetitions of spin coating and pyrolysis.

\subsection{Difference in crystal orientation in relation to RTA temperature}

The XRD spectra of the PZT film obtained from Sol-A with different RTA temperatures are shown in Fig. 5. In this subsection, the number $N$ of the processes in Fig. 1 is 1, drying is performed at $180{ }^{\circ} \mathrm{C}$ for $2 \mathrm{~min}$, and pyrolysis is performed at $350{ }^{\circ} \mathrm{C}$ for $5 \mathrm{~min}$. No noticeable difference is observed in the PZT film orientation even at a relatively low RTA temperature of $550{ }^{\circ} \mathrm{C}$ or a very high temperature of $750{ }^{\circ} \mathrm{C}$. Strong peaks correspond to (101)/(110) and (111). The highest (111) peak is obtained when the RTA temperature is $650^{\circ} \mathrm{C}$.

The XRD spectra of the PZT film obtained from Sol-B are shown in Fig. 6. At an RTA temperature of $600{ }^{\circ} \mathrm{C}$ or less, the peak of the perovskite phase is not prominent, and the peak of the non-piezoelectric pyrochlore phase appears at about $29^{\circ}$. At RTA temperatures of 650 and $700{ }^{\circ} \mathrm{C}$, the (111) peak mainly appears. On the other hand, at an RTA temperature of $750^{\circ} \mathrm{C}$, the (110)/(101) peaks appear and the (111) peak becomes slightly weak.

The XRD spectra of the PZT film obtained from Sol-C are shown in Fig. 7. At an RTA temperature of $550{ }^{\circ} \mathrm{C}$, no peak of the perovskite phase is observed, but the peak of the pyrochlore phase appears. When the RTA temperature is in the range from 600 to $750{ }^{\circ} \mathrm{C}$, the peaks appear similar, but the peak of (101)/(110) appears strong at RTA temperatures of 650 and $700{ }^{\circ} \mathrm{C}$. From the above results, the RTA temperature of $650{ }^{\circ} \mathrm{C}$ is judged to be suitable for all sols.

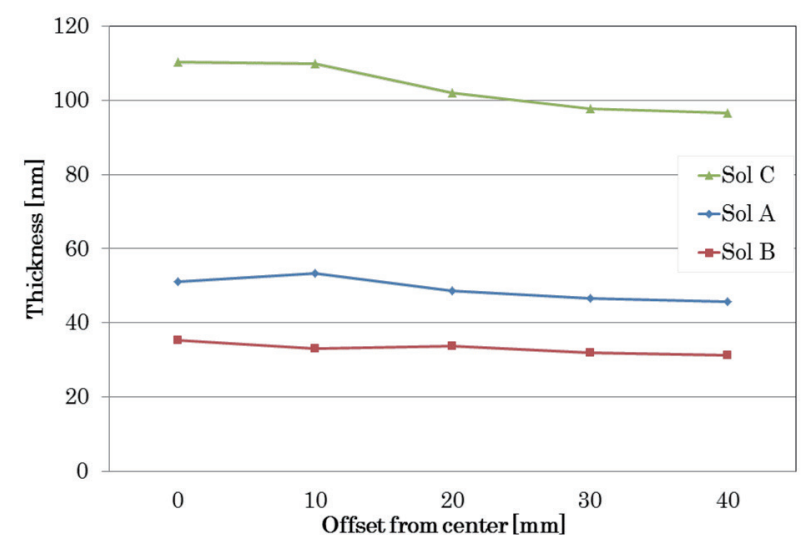

Fig. 4. (Color online) PZT film thickness per spin coating. 


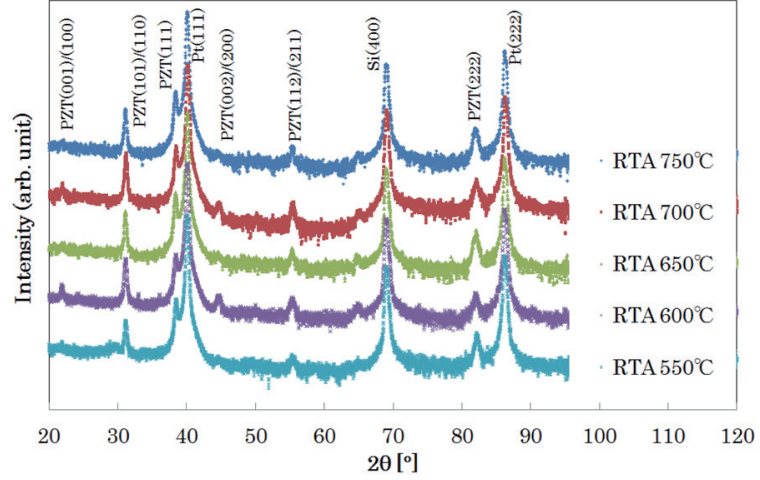

Fig. 5. (Color online) XRD spectra of PZT film from Sol-A for different RTA temperatures.

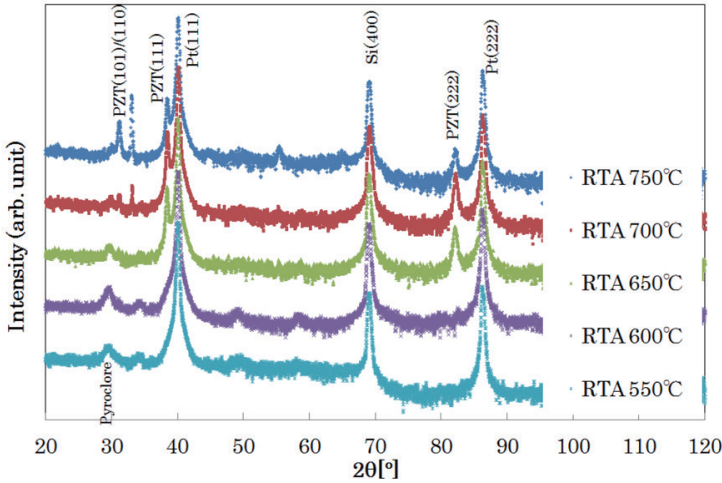

Fig. 6. (Color online) XRD spectra of PZT film from Sol-B for different RTA temperatures.

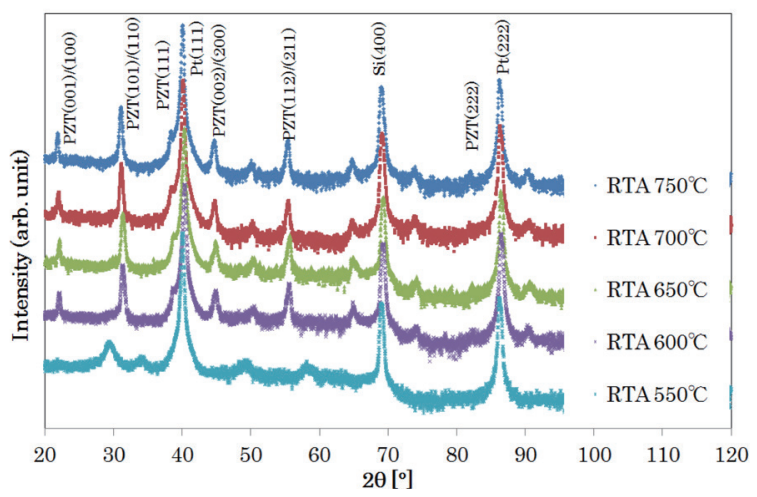

Fig. 7. (Color online) XRD spectra of PZT film from Sol-C for different RTA temperatures.

\subsection{Difference in crystal orientation in relation to drying temperature}

The XRD spectra of the PZT film obtained from Sol-A with different drying temperatures are shown in Fig. 8. The RTA temperature is $650{ }^{\circ} \mathrm{C}$ hereinafter. Although the peak intensities somewhat depend on the drying temperature, there is no change in the crystal orientation. The (111) and $(110) /(101)$ peaks appear strongest at drying temperatures of 150 and $180{ }^{\circ} \mathrm{C}$, respectively. All peaks are weak at a drying temperature of $210{ }^{\circ} \mathrm{C}$.

The XRD spectra of the PZT film obtained from Sol-B are shown in Fig. 9. Although there is almost no dependence of the crystal orientation on the drying temperature, the (111) peak is slightly smaller at a drying temperature of $120^{\circ} \mathrm{C}$. The XRD spectra of the PZT film obtained from Sol-C are shown in Fig. 10. The (100)/(001), (101)/(110), and (111) peaks are observed, and there is no significant difference in the crystal orientation among drying temperatures. The $(101) /(110)$ peak is strongest at a drying temperature of $180{ }^{\circ} \mathrm{C}$. From the above results, a drying temperature of $180^{\circ} \mathrm{C}$ is deemed suitable for each sol. 


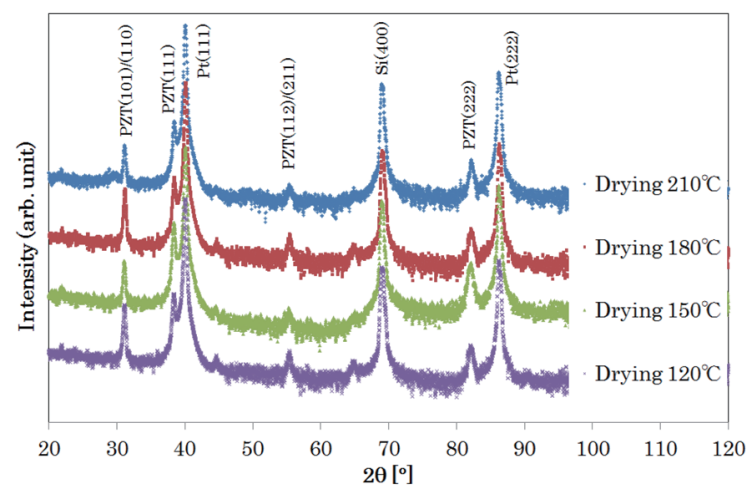

Fig. 8. (Color online) XRD spectra of PZT film from Sol-A for different drying temperatures.

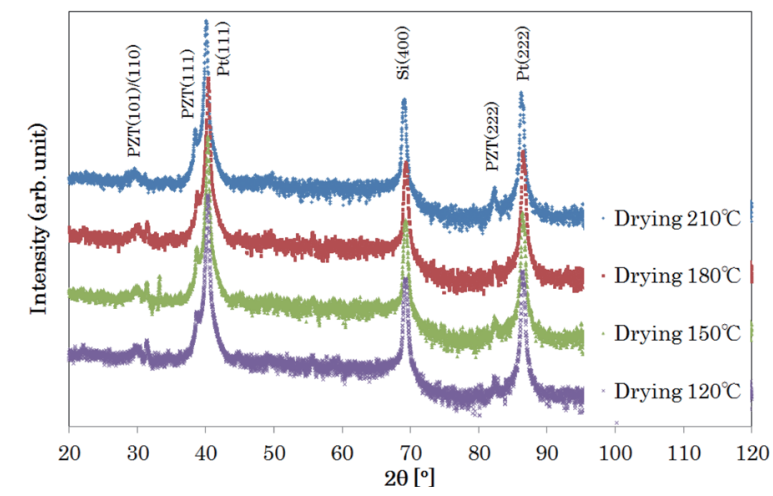

Fig. 9. (Color online) XRD spectra of PZT film from Sol-B for different drying temperatures.

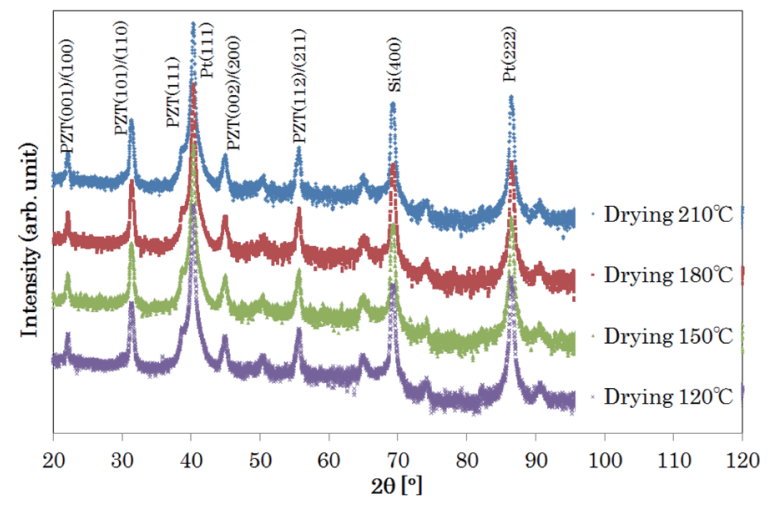

Fig. 10. (Color online) XRD spectra of PZT film from Sol-C for different drying temperatures.

\subsection{Difference in crystal orientation in relation to sol-gel solution}

The process conditions for each sol optimized using the results of the above-mentioned experiments are summarized in Tables 2 and 3. Table 2 shows the conditions for spin coating, drying, pyrolysis, and RTA. Table 3 shows the numbers of process repetitions, $N$ and $M$. The resulting film thickness is about $0.9 \mu \mathrm{m}$ for each sol, and there is a thickness distribution of 5 to $10 \%$ in the radial direction. Later, we found the reason for this thickness distribution, as will be discussed in Sect. 4. The deposition times under the process conditions are about $6 \mathrm{~h}$ for Sol-A and Sol-B, and $3 \mathrm{~h}$ for Sol-C. It can be shortened by optimizing the tool operation.

The XRD spectra of Samples A, B, and C, which were prepared under the conditions in Tables 1 and 2, are shown in Figs. 11, 12, and 13, respectively. For Sample A, the peaks are strongly dependent on the wafer radial position. The (111) and (101)/(110) peaks appear strong at the center and at a radius of $20 \mathrm{~mm}$, whereas the (111) and (100)/(001) peaks appear strong at a radius of $40 \mathrm{~mm}$. In addition, many peaks appear prominent in Fig. 11 compared with Fig. 5 for the thinner films $(M=3$ and $N=1)$. 
Table 2

Deposition conditions for PZT film.

\begin{tabular}{cccc}
\hline Spin coating & Drying & Pyrolysis & RTA \\
\hline $3000 \mathrm{rpm}$ & $180{ }^{\circ} \mathrm{C}$ & $350{ }^{\circ} \mathrm{C}$ & $650{ }^{\circ} \mathrm{C}$ \\
$20 \mathrm{~s}$ & $2 \mathrm{~min}$ & $5 \mathrm{~min}$ & $10 \mathrm{~min}$ \\
\hline
\end{tabular}

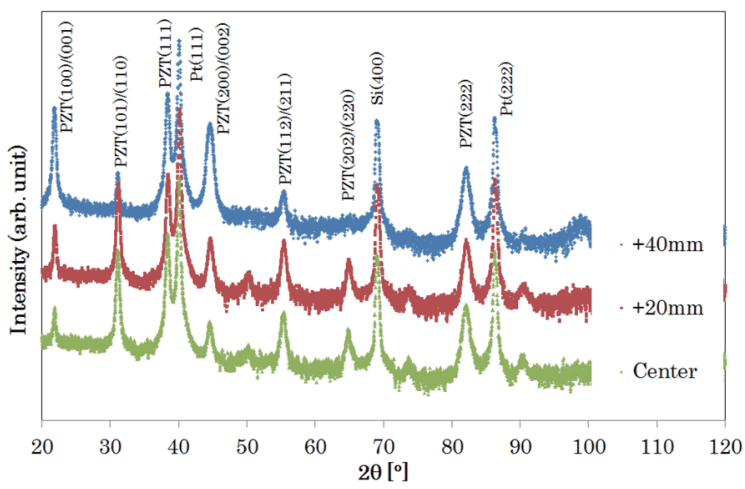

Fig. 11. (Color online) XRD spectra of $1-\mu \mathrm{m}$-thick PZT film from Sol-A.
Table 3

Number of process repetitions for $1 \mu \mathrm{m}$ PZT film.

\begin{tabular}{lcc}
\hline & $\begin{array}{c}M \text { (Spin coating } \\
\text { to pyrolysis) }\end{array}$ & $\begin{array}{c}N(\text { Spin coating } \\
\text { to RTA }=\text { unit process })\end{array}$ \\
\hline Sol-A & 3 times & 6 times \\
Sol-B & 5 times & 5 times \\
Sol-C & 3 times & 3 times \\
\hline
\end{tabular}

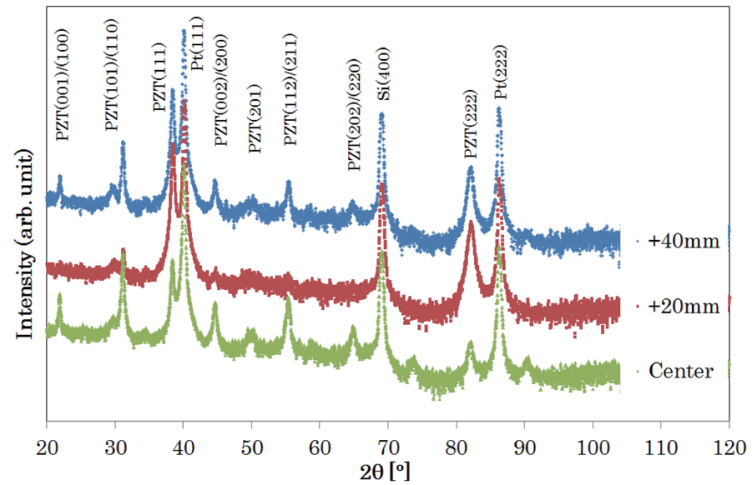

Fig. 12. (Color online) XRD spectra of $1-\mu \mathrm{m}$-thick PZT film from Sol-B.

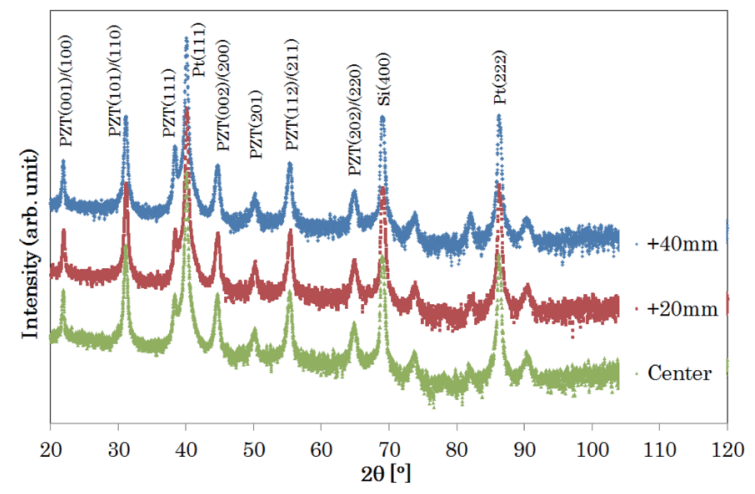

Fig. 13. (Color online) XRD spectra of 1- $\mu$ m-thick PZT film from Sol-C.

For Sample B, there appears a single orientation of (111) at a radius of $20 \mathrm{~mm}$. At the center and at a radius of $40 \mathrm{~mm}$, however, there are multiple crystal orientations including (101)/(110). For Sample C, there are various peaks and the radial position dependence of the XRD spectrum is small. This is also the case with the thinner film $(M=3$ and $N=1)$ shown in Fig. 7.

From the above results, it is clear that there is a radial position dependence of crystal orientation and crystallinity, which must be addressed by improving the tool and process recipe. 


\subsection{Ferroelectric characteristics}

Figure 14 shows the ferroelectric characteristics of Samples A, B, and C, which were measured at radii of 5 and $20 \mathrm{~mm}$. The coercive electric field $\left(E_{c}\right)$ is about $\pm 50 \mathrm{kV} / \mathrm{cm}$ for all samples. On the other hand, the saturation polarization $\left(P_{s}\right)$ and residual polarization $\left(P_{r}\right)$ are different for each sample. $P_{s}$ is $32 \mu \mathrm{C} / \mathrm{cm}^{2}$ for Sample A, $23 \mu \mathrm{C} / \mathrm{cm}^{2}$ for Sample B, and $37 \mu \mathrm{C} / \mathrm{cm}^{2}$ for Sample C. $P_{r}$ is $7 \mu \mathrm{C} / \mathrm{cm}^{2}$ for Samples A and B, and $15 \mu \mathrm{C} / \mathrm{cm}^{2}$ for Sample C. These differences in $P_{S}$ and $P_{r}$ are mainly affected by the sol rather than the position on a wafer, as described later.

\subsection{Piezoelectric constant}

Figures 15, 16, and 17 show displacement in the thickness direction and polarization as functions of electric field applied to the PZT films for Samples A, B, and C, respectively. The displacement was measured by the double-laser-beam piezoelectric measurement system. No poling was performed for any sample. From the results, the piezoelectric constant $d_{33, f}$ was calculated and the results are shown in Table 4.

For MEMS applications, the piezoelectric constant $d_{31}$ is often more important than $d_{33, f}$. In general, the two piezoelectric constants have the relationship $d_{33, f} \cong d_{31} \times 2-2.5$. The piezoelectric constant $d_{31}$ can be directly estimated by measuring the displacement of a cantilever, ${ }^{(12)}$ but we did not use this method in this study. Makimoto et al. showed $d_{33, f} \cong d_{31} \times 2-2.5$ in the case of pulse poling at above $120 \mathrm{~V}$ for $1.8-\mu \mathrm{m}$-thick PZT films, and $d_{33, f} \cong d_{31} \times 0.9$ for pulse poling at $20 \mathrm{~V}^{(13)}$ This electric field is lower than that with full poling such as at $100 \mathrm{~V}$. Therefore, on the basis of the latter relationship, $d_{31}$ is estimated to be approximately $75 \mathrm{pm} / \mathrm{V}$ for Samples A and B and $85 \mathrm{pm} / \mathrm{V}$ for Sample C, because no intentional poling was carried out in this study.

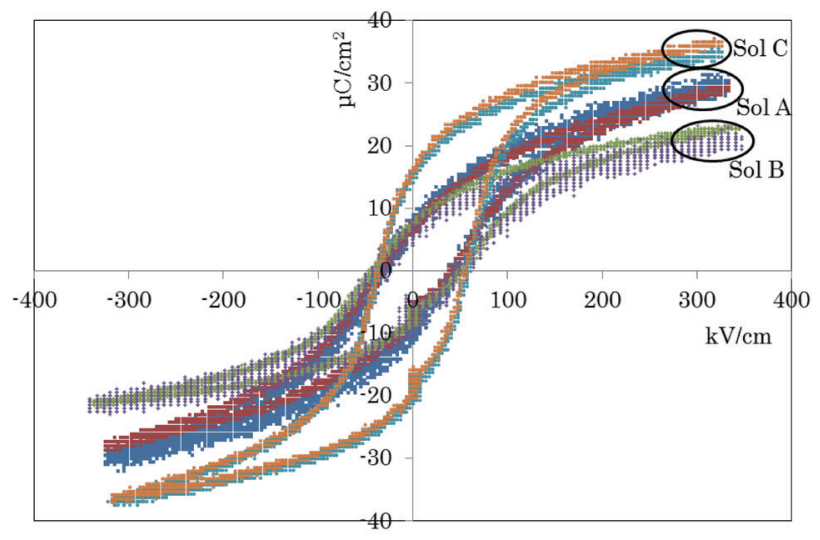

Fig. 14. (Color online) Ferroelectric property for each sol. 


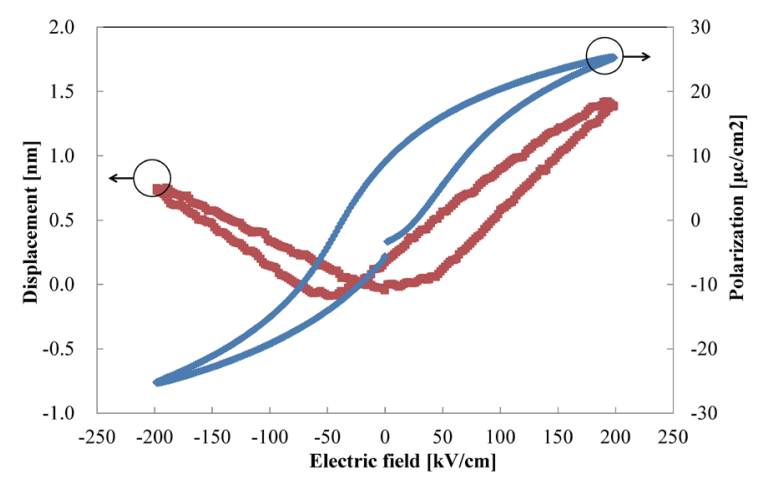

Fig. 15. (Color online) Displacement in the thickness direction and polarization as functions of electric field applied to the PZT film from Sol-A.

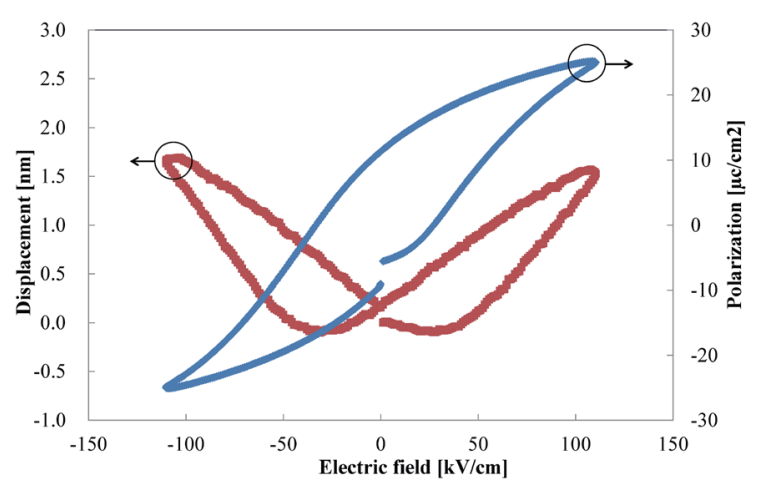

Fig. 17. (Color online) Displacement in the thickness direction and polarization as functions of electric field applied to the PZT film from Sol-C.

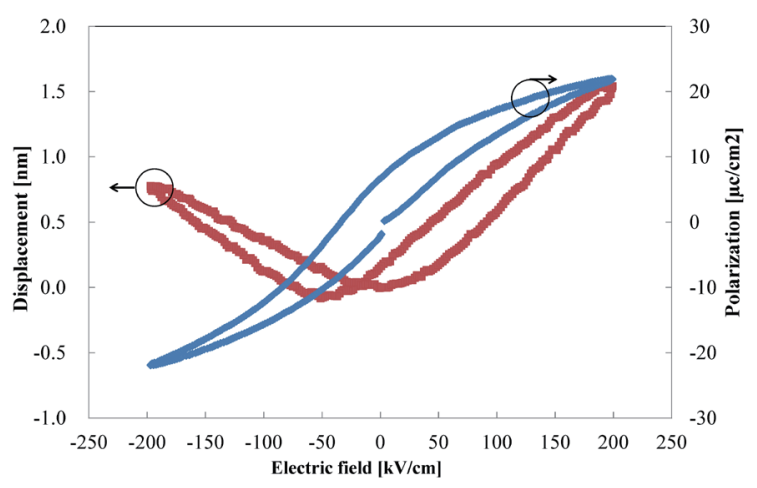

Fig. 16. (Color online) Displacement in the thickness direction and polarization as functions of electric field applied to the PZT film from Sol-B.

Table 4

Measurement of $d_{33, f}$ parameter for each sol.

\begin{tabular}{lcc}
\hline No. & PZT film $(\mathrm{nm})$ & $d_{33, f+(\mathrm{pm} / \mathrm{V}) 1 \mathrm{kHz} \pm 20 \mathrm{~V}}$ \\
\hline Sol-A & 970 & $60-67$ \\
Sol-B & 1190 & $63-67$ \\
Sol-C & 1870 & 75,76 \\
\hline
\end{tabular}

\section{Film Thickness Uniformity}

In general, one of the advantages of the sol-gel method over sputter deposition is the good uniformity of the film thickness within a wafer. As shown in Fig. 4, however, the variation of the film thickness is as large as 5 to $10 \%$ within one wafer in this study. To address this problem, two modifications were made on the deposition tool.

In all experiments mentioned above, the setup shown in Fig. 18(a) was used. There was a lid with a 15-mm-diameter hole on a spinner. A nozzle was passed through the hole to provide the sol access to the wafer. When the wafer is rotated, air may be introduced from the hole owing to the dragging effect induced by wafer rotation, and the center part of the wafer may dry faster than the periphery, resulting in a larger thickness at the center. On the basis of this assumption, the first modification has removed the lid, as shown in Fig. 18(b). 


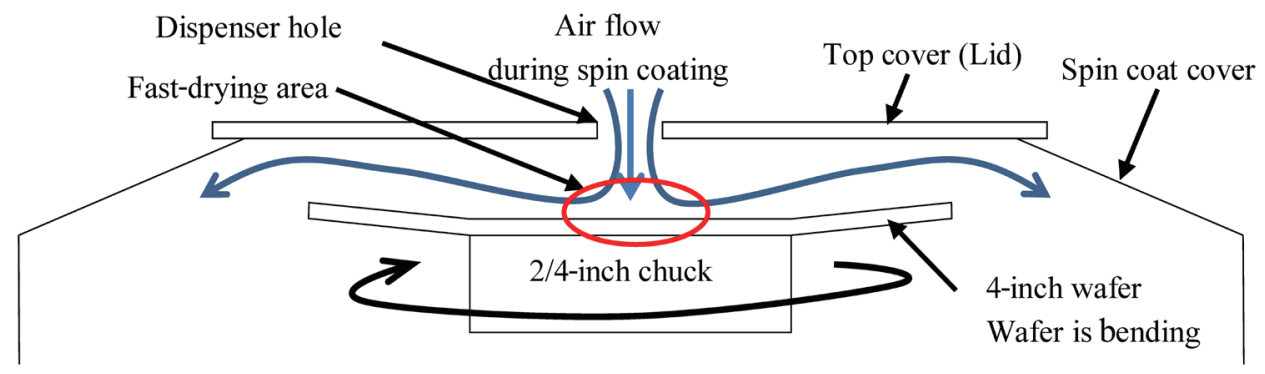

(a)

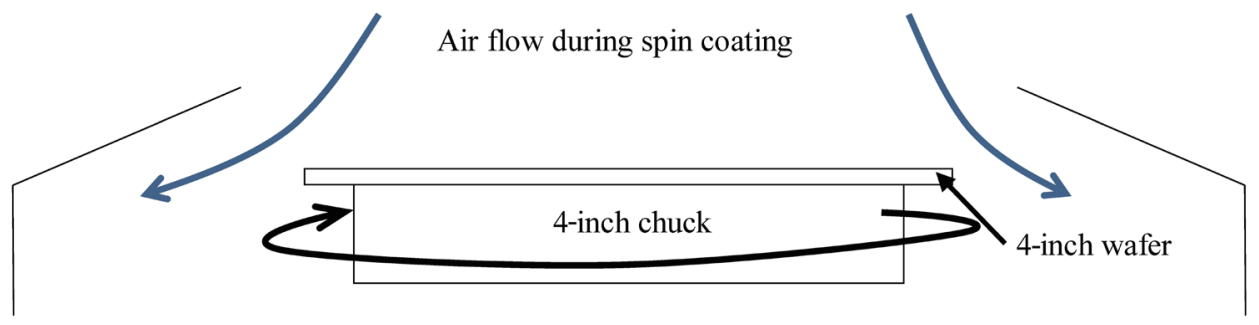

(b)

Fig. 18. (Color online) Mechanism behind film thickness distribution in spin coating. (a) Before optimization. (b) After optimization: Top cover removed.

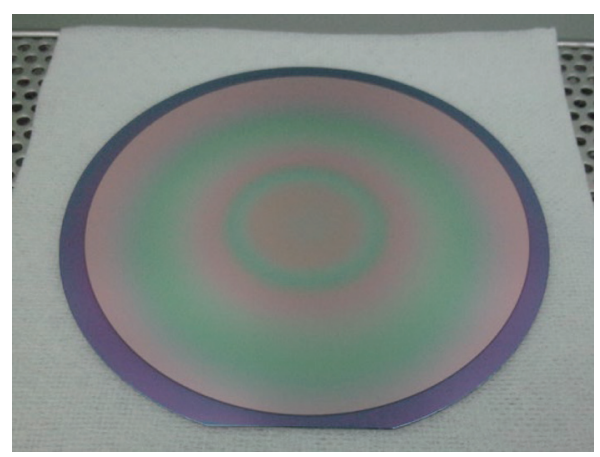

Fig. 19. (Color online) PZT-coated wafer before optimization of sol-gel deposition. Interference colors are visible.

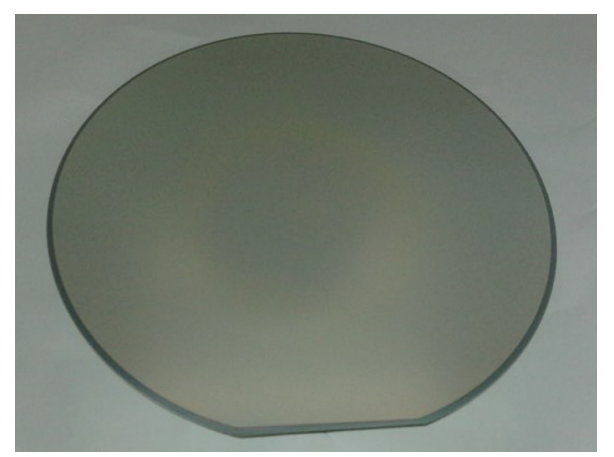

Fig. 20. (Color online) PZT-coated wafer after optimization of sol-gel deposition. No interference colors are visible.

The other modification concerns the size of the wafer chuck. In all experiments mentioned above, the chuck was $50 \mathrm{~mm}$ in diameter. A bowing 4-inch wafer is chucked almost as is, which may result in unevenness of the film thickness during spin coating. On the basis of this assumption, the diameter of the wafer chuck was increased to $100 \mathrm{~mm}$.

Figures 19 and 20 show PZT-coated wafers before and after optimization, respectively. It is visually clear that the film uniformity has been significantly improved. The improved film uniformity is about $2 \%$ within a 4 -inch wafer, as shown in Fig. 21. 


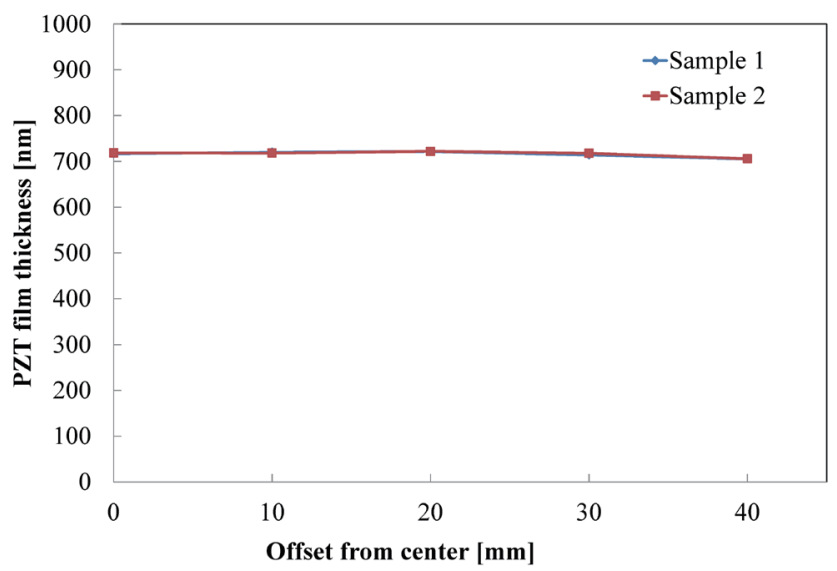

Fig. 21. (Color online) PZT film thickness per spin coating after tool modification.

\section{Conclusions}

Three PZT sols from different manufacturers were compared using an automatic sol-gel deposition tool. Drying and RTA temperatures were investigated by XRD, and it was found that an RTA temperature of $650{ }^{\circ} \mathrm{C}$ and a drying temperature of $180{ }^{\circ} \mathrm{C}$ were suitable for each sol. After the process parameters were fixed, a PZT film of about $1 \mu \mathrm{m}$ thickness was prepared on a 4-inch wafer from each sol. The crystal orientations, the ferroelectric characteristics, and the piezoelectric constant $d_{33, f}$ were evaluated for the three samples. The piezoelectric constant $d_{33, f}$ was approximately $65 \mathrm{pm} / \mathrm{V}$ for Sol-A and Sol-B and $75 \mathrm{pm} / \mathrm{V}$ for Sol-C without poling. The piezoelectric constant $d_{31}$ after poling may be 75 and $85 \mathrm{pm} / \mathrm{V}$, respectively, on the basis of on a previous study. ${ }^{(12)}$

In this study, the uniformity of film thickness was 5 to $10 \%$ within a 4 -inch wafer, which was worse than expected for the sol-gel method. Thus, the sol-gel deposition tool was modified by removing the lid on the spinner and wafer chuck, and the uniformity was finally improved to $2 \%$ within a wafer. The improved sol-gel deposition tool is commonly used with the recipes developed in this study.

\section{Acknowledgments}

This study was partly supported by the Nanotechnology Platform (MEXT) and JSPS KAKENHI Grant Number 18H01390. The authors would like to thank Ms. Natsumi Makimoto and Dr. Ken Kobayashi of the National Institute of Advanced Industrial Science and Technology (AIST) for their help in the measurement of piezoelectric constants.

\section{References}

1 J. Baborowski: J. Electroceram. 12 (2004) 33.

2 S. Koganezawa, Y. Uematsu, T. Yamada, H. Nakano, J. Inoue, and T. Suzuki: IEEE Trans. Magn. 35 (1999) 988 . 
3 J. Lappalainen, J. Frantti, H. Moilanen, and S. Leppävuori: Sens. Actuators, A 46 (1995) 104.

4 Y. Yin, H. Ye, W. Zhan, L. Hong, H. Ma, and J. Xu: Sens. Actuators, A 171 (2011) 332.

5 Q. Q. Zhang, S. J. Gross, S. Tadigadapa, T. N. Jackson, F. T. Djuth, and S. Trolier-McKinstry: Sens. Actuators, A 105 (2003) 91.

6 Y. Soeno, S. Ichikawa, T. Tsuna, Y. Sato, and I. Sato: IEEE Trans. Magn. 35 (1999) 983.

7 J. F. Roeder, T. H. Baum, S. M. Bilodeau, G. T. Stauf, C. Ragaglia, M. W. Russell, and P. C. van Buskirk: Adv. Mater. Opt. Electron. 10 (2000) 145.

8 C. V. R. Vasant Kumar, M. Sayer, R. Pascual, D. T. Amm, Z. Wu, and D. M. Swanston: Appl. Phys. Lett. 58 (1991) 1161.

9 T. Iijima, S. Osone, Y. Shimojo and H. Nagai: Int. J. Appl. Ceram. Technol. 3 (2006) 442.

10 M. Moriyama, Y. Kawai, S. Tanaka, and M. Esashi: IEEJ Trans. Sens. Micromach. 132 (2012) 282.

11 S. Sivaramakrishnan, P. Mardilovich1, A. Mason, A. Roelofs, T. Schmitz-Kempen, and S. Tiedke: Appl. Phys. Lett. 103 (2013) 132904 (in Japanese).

12 C. H. J. Fox, X. Chen, H. W. Jiang, P. B. Kirby, and S. McWilliam: Proc. SPIE 4700 (2002) 40.

13 N. Makimoto, T. Takeshita, R. Maeda, and K. Kobayashi: JSAP Spring Meeting, 2015 (in Japanese). 